\title{
The Effect of SiC Addition on AlNi Compact Mechanical Properties Produced Via Powder Metallurgy
}

\author{
Ali Hubi Haleem \\ Nawar Fahem Kadhem. \\ College of Materials Engineering, Babylon University, Babylon, Iraq \\ alialihhhobi@gmail.com
}

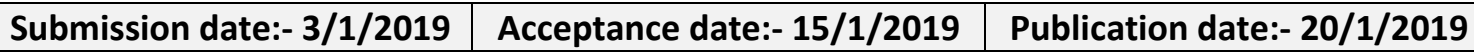

\begin{abstract}
:
This research directed to produce Al-Ni alloys by powder metallurgy technique since of its marketable and industrial significant. Nickel and aluminum powders were determined their particle size then the powders mixed and blended with percent (Al - 20\% Ni). Silicon carbide particles (SiC) powder supplemented to master alloy powder by percent (4-6- and $8 \mathrm{wt}$. \%) separately then these powders mixed to obtain homogeneous distribution, then the powders compacted in cold pressure at $700 \mathrm{MPa}$. The sintering procedure was performed at $\left(530^{\circ} \mathrm{C}\right)$ for $8 \mathrm{hrs}$. At vacuum atmosphere $\left(10^{-4}\right.$ torr). After cooling these samples grinded and polished to estimate microstructure, density, porosity, LOM, SEM, EDS, X-ray diffraction ,hardness and wear tests at dissimilar circumstances. Results showed that the hardness increased by $(52 \%)$ and wear rate decreased by $(55 \%)$ at 8 wt $\%$ silicon carbide addition, and it was the best results.
\end{abstract}

Key words: AMMCs' Composite Material, Aluminum Nickel Alloys, Powder Technology.

\subsection{Introduction}

Aluminum being the main matrix, it was authoritative that the composite controlled advanced hardness and wear resistant that would allow its practice in more difficult applications. Thus, silicon carbide was selected to advance the tribological possessions. To additional advance the corrosion resistance of aluminum, Nickel, which have excellent resistant to chemical spells, was selected as the reinforcement material. Silicon carbide $(\mathrm{SiC})$ is a absolutely wear resistant material with extra mechanical characterizations, good thermal shock resistant. It is in extensive use in business and is fairly easy to production. $\mathrm{SiC}$ is available in dissimilar arrangements, as powder or in grinding wheels, cutters, etc. The main use of nickel is, they are characterized by improved strength, ductility, and resistant to corrosion ambient. It is a silver-white, hard, easy, and soft metal. The choice of matrix material depends on the submission. Sunny matrix materials are easy to manufacture. Hereafter alloy constructions for example aluminum, copper, iron and steels, and titanium have been selected as matrixes. The designed for this scheme was pure aluminum [1,2].

Aluminum is a metal that has uses in often all arenas of engineering and ordinary life, thanks to its good general properties like low weight/density, good strength, good thermal and electrical conductivity, good corrosion resistance, and informal obtainability. Aluminum and its alloys and composites are being used to power today's cars, aircraft, space technology, nautical applications, MEMs, and nano-technology. Aluminum is very simple to recycle. Aluminum is the most common choice of matrix for MMCs. In order to manufacture more environment automobiles, the fuel domestic plays an energetic role. To reach this, lightweight composites are being used to encourage weight redeemable. The most of automotive trades uses glass-reinforced plastics to save prices low, some apparatuses like wheel rims and inlet manifolds could be shaped using these. Sports applications have seen the widest use of composites since their discovery. Composites like carbon fiber, FRPs, boron fiber show quite a lot of potential for making stronger, lighter, and stiffer equipment [3].

\subsection{Experimental Work:}

The samples used in this study were prepared using powder metallurgy method where powders were used (Aluminum, nickel, silicon carbide), Table (1) shows the purity, Particle size and origin of the powders used. 


\subsection{Powders Preparation:}

Mixing of elemental powders has been done by using ball mill shown in the Fig. (1). Stainless steel balls with different diameters $(10 \mathrm{~mm}$ and $5 \mathrm{~mm})$ have been used to mix and refine metal powders for about 6 hours and 3500rpm according to Kotresh, procedure [4]. The ball-to powder weight ratio was $3: 1$ by weight [5]. The increment in the number of contact areas between the elemental powder particles enhances the mixing process. Wet mixing is done by using $0.5 \mathrm{cc}$ of ethyl alcohol to every 25 $\mathrm{g}$ of powder mixture. The wet mixing is used to minimize the temperature generated by friction between the balls with walls and powder. After mixing the wet mixtures.

\subsection{Powders Compaction}

Electric uniaxial hydraulic press is used to compact the blended powder to green samples with dimensions $(\mathrm{D}=12.75 \mathrm{~mm}$ and $\mathrm{t} \approx 5-6.5 \mathrm{~mm}$ ) that used for the tests. The die used was single action die made from stainless steel, Graphite has been used as lubricant in order to minimize the friction between the punch and the die wall as well as the friction between the green compact and the die wall and to avoid the cracks initiated from the ejecting of green compact. The pressure was (800) MPa with loading rate $(8 \mathrm{ton} / \mathrm{min}$ ) and period of applied pressure time is (4 min) has been used in order to determine the optimum compression stress that gives higher density and low green porosity.

\subsection{Sintering of Compacts:}

After the samples were produced, the sintering treatment was done at $530^{\circ} \mathrm{C}$ for 8 hours and using a vacuum atmosphere. The samples were then left inside the oven to be cooled. with thermal cycle shown in Fig. (2).

\subsection{Testes of Samples :}

\subsubsection{Physical Tests}

Several physical tests for elemental powders, green compacts, and sintered samples. These tests include the following:

\section{*Particle Size Analysis}

Particle size analysis has been done for all elemental powders ( $\mathrm{Al}, \mathrm{Ni}, \mathrm{SiC})$ by using laser particle size analyzer using distilled water as a dispersion medium. The test has been done in the collage of materials engineering - Ceramic department laboratories.

\section{*Green Density and Green Porosity}

The green density of the compact can be expressed by the mass per unit volume of compacted mixed powder.

\section{*Density and Porosity after sintering of Compacts}

The density and porosity of samples were calculated according to ASTM B-328 [6]: The test has been done for all samples in order to study the effect of an alloying element on the porosity.

\subsubsection{Microstructure Characterization}

\section{*Light Optical Microscopy Observation}

Microstructure observation has been done for sintered samples with different magnifications (100X , 200X , 400X , 800X ) using light optical microscope with high resolution camera fixed in the microscope used to capture photos. The prepared samples were with dimensions $(\mathrm{D}=12.75 \mathrm{~mm}, \mathrm{t}=5 \sim 7$ $\mathrm{mm}$ ) has been wet grinding using $(1000,1200,1500,2000,2500)$ grit silicon carbide papers using grinding wheel machine and then polishing by using polishing paper and diamond with 1-3 $\mu \mathrm{m}$ particle size, These samples are then cleaned with water and dried with hot air the Samples are then etched with were Keller's reagent $(1 \% \mathrm{HF}+1.5 \% \mathrm{HCl}+2.5 \mathrm{HNO} 3+95 \% \mathrm{H} 2$ O) [7]to reveal the microstructures clearly for about $40 \mathrm{sec}$. After that, the samples are ready to use for microscopic observation as shown figure (3). 


\section{*Scanning Electron Microscopy (SEM) and Energy Dispersive Spectroscopy (EDS)}

Scanning electron microscope observation is used to reveal the microstructure of etched sintered samples, Several magnification has been captured with (200X, 1000X ,2000X ,5000X and 10000X) KV for nickel aluminum samples without and with $8 \mathrm{wt} . \% \mathrm{SiC}$ as shown figures 4 and 5,And Energy dispersive analysis has been done for nickel aluminum samples without and with 8 wt.\% SiC. Two to three areas have been taken for each sample as shown in Figures(6 -7). SEM examination has been done in The Ministry of Science and Technology / Materials Research Department. And Qualification in Baghdad ,Iraq.

\section{*X-Ray Diffraction (XRD)}

X-ray diffraction has been used to identify and analysis the phases exist in the prepared alloys as shown in fig. (8), this test has been done for sintered samples. X-ray diffraction and Energy Dispersive Spectroscopy tests are carried out in The Ministry of Science and Technology / Materials Research Department. Low angle $\mathrm{X}$-ray diffraction is performed and $\mathrm{X}$-ray generator with $\mathrm{Cu} \mathrm{K} \alpha$ radiation at( $40.0 \mathrm{Kv})$ and $(30.0 \mathrm{~mA})$ is used.

\subsubsection{Mechanical Tests}

\section{*Brinell Micro hardness Measurement}

Macro hardness Brinell tester is used to measure the hardness of the samples with $(31.25) \mathrm{kp}$ as applying weight and the Incubation time was $(10 \mathrm{sec})$ in the state applied weight and diameter (2.5mm). Three reading for each sample had been taken and the average value used to analysis the behavior of the alloys.

\section{*Dry Slide Wear Test}

The dry sliding wear is studied by using the pin on disk concept using (300 rpm) and constant radius $(6.5 \mathrm{~mm})$ with different sliding distance and the loads were $(10,20$ and $30 \mathrm{~N})$. The sample is weighted before and after a period of time $(5,10,15$ and $20 \mathrm{~min})$, using (0.0001) accuracy electric balance the wear instrument that was used in this work are shown in Fig. (9).

\subsection{Results and discussion:}

Figure 10 showed that when increasing pressure, the green density increases too until it reaches a certain limit at which any further increase in the pressure has no or little effect on its value, that was due to the increasing forces causing porosity to close up and it also leads to reduced green porosity as in fig.(11). So the preferred pressure was determined as $700 \mathrm{MPa}$ for all the samples prepared in the present study. Density after sintering also increases and also leads to lower porosity after sintering. This parameter will lead to less porosity as shown figures (12) and (13) respectively. This is because the sintering at $530 \mathrm{C}^{\circ}$ for $8 \mathrm{hr}$ increases diffusion and reduces voids that increase the contact points between particles [8]. The results of the microstructure examination show that the phase (Al3Ni2 ) is formed between aluminum and nickel which reduces the expansion of pores by filling the granules of this phase of the vacancies and gaps formed between the grains of the planet [9].

In the current study the hardness of the samples of all alloys after sintering are measured by Brinell hardness test , and the greatest value was recorded for aluminum nickel reinforced with 8 wt $\%$ $\mathrm{SiC}$ as shown fig.(14).This increment could be attributed to the high hardness of $\mathrm{SiC}$ particles itself which acting as barriers to dislocation motion and strengthens the structure of the samples [10].

Samples with (12.75) mm diameter exposed to wear test beneath different loads (10, 20 and30) $\mathrm{N}$ and for different times $(5,10,15$ and 20) $\mathrm{min}$ at room temperature. Weight loss was altered to volume loss using the experimental density of each composite sample which was measured in density test. that volume loss is increased with increasing the practical load, where the highest volume loss was documented under $(30 \mathrm{~N})$ and vice versa. This is expected performance, where the increase in load pointers to increase the friction between sample surface and the revolving disk [11]. Also, the volume loss was enlarged with increasing time owing to the increase of sample's mass loss with increasing friction time. Figures (15) to (17) exhibit the outcome of SiC particles adding on wear rates at un-similar circumstances. From these figures, it can be seen that volume loss was decreased severely with increasing $\mathrm{SiC}$ percentage, even it extents the minimum value at the composite that have maximum $\mathrm{SiC}$ percentage $(8 \%)$. This may owing to the role of SiC particles in 
obstructive dislocation motion sso, hardness was increased and there by wear resistance was also increased[12]. Figures (18 - 20) showed the wear rate for all sample with and without SiC particles.

Figures(18 - 20) shows, That at $10 \mathrm{~N}$ the highest wear rate in aluminum nickel sample and the wear rate is decreased by $57 \%$ for aluminum nickel reinforced with $8 \mathrm{wt} \%$ SiC samples, At $20 \mathrm{~N}$ the highest wear rate in aluminum nickel sample and the wear rate is decreased by $78 \%$ for aluminum nickel sample reinforced with $8 \mathrm{wt} \% \mathrm{SiC}$, At $30 \mathrm{~N}$ the highest wear rate in aluminum nickel sample and the wear rate is decreased by $55 \%$ at aluminum nickel reinforced with 8 wt $\%$ SiC samples.

\subsection{Conclusions:}

1. The sintering process at $530^{\circ}$ for $8 \mathrm{hrs}$ of master $\mathrm{Al}-20 \% \mathrm{Ni}$ alloys with different compacting pressure is effective enough to complete the transformation of $\mathrm{Al}$ and $\mathrm{Ni}$ powder to alloy structure and resulted the $\mathrm{Al}_{3} \mathrm{Ni}_{2}$ phase.

2. The increasing in compacting pressure from (400 to 800) $\mathrm{MPa}$ for master alloy $\mathrm{Al}-20 \% \mathrm{Ni}$ resulted increasing in density and decreasing in porosity.

3. Powder metallurgy is an effective method in manufacturing of metal matrix composites, where the optical microscope and SEM images showed uninform distribution of silicon carbide particles in the Al-20\% Ni alloys.

4. Brinell hardness significantly enhanced with addition of silicon carbide particles to Al-20\% Ni alloys, the variation percentages comparing with master alloys are increased with addition of silicon carbide particles by $(27 \%),(46 \%)$ and $(52 \%)$ for samples of $(4 \mathrm{wt} \%),(6 \mathrm{wt} \%)$ and $(8 \mathrm{wt} \%)$ silicon carbide respectively.

5. Wear rate is decreased with the additions of silicon carbide particles by $23 \%, 41 \%$ and $58 \%$ for samples of 4, 6, and $8 \mathrm{wt}$.\% $\mathrm{SiC}$ respectively under $30 \mathrm{~N}$ and $20 \mathrm{~min}$.

\section{CONFLICT OF INTERESTS.}

- There are no conflicts of interest.

\subsection{References:}

[1] M. K. Surappa, " Aluminium Matrix Composites: Challenges and Opportunities", Sadhan, Vol. 28, Parts 1 and 2, PP: $319-334,2003$.

[2] V. Ravi Kumar, B. P. Dileep, and H. R. Vital, Tribological and mechanical characterization of AlNi-SiC metal matrix composites, AIP Conference Proceedings, 2017.

[3] M. R. Vaezi, S. K. Sadrnezhaad, and L. Nikzad, Electrodepositing of Ni-SiC nano-composite coatings and evaluation of wear and corrosion resistance and electroplating characteristics, Colloids and Surfaces A: Physicochem. Eng. Aspects 315, pp. 176- 182, 2008.

[4] M. Kotresh, and M. Benal, "Copper Based Shape Memory Alloy for Reinforcement into Adaptive Composite", International Journal of Innovative Research in Advanced Engineering, ISSN: 23492163 Volume 1 Issue 8, 2014.

[5] P. Sajjad, N. i Mohammad, , P. Nader, M. Seyed, Z. Mahdi, and E. Hamid, "Manufacturing and evaluating $\mathrm{Cu}$-based shape memory alloy by hot extrusion of PM samples made by mechanica alloying “, Amirkabir University of Technology, Iran, 2012.

[6] ASTM B - 328 ' Standard test method for density, Oil content, and interconnected porosity of sintered metal structural parts and oil - impregnated bearing ', ASTM International, 2003.

[7] B. P. Dileep, " Mechanical and Corrosion Behavior of Al-Ni-SiC Metal Matrix Composites by Powder Metallurgy", Department of mechanical engineering, Amrita School of Engineering, Bengaluru, Amrita Vishwavidyapeetham, Amrita University. India, 2018.

[8] F. Prusa, D. Vojtech, A. Michalcova, and I. Marek," Mechanical properties and thermal stability of $\mathrm{Al}-\mathrm{Fe}-\mathrm{Ni}$ alloys prepared by centrifugal atomization and hot extrusion", Mat. Sci. Eng. A Struct. 603, 141, 2014. 
[9] A. D. Setyawan, D. V. Louzguine, K. Sasamori, H. M. Kimura, S. Ranganathan ، and A. Inoue, "Phase composition and transformation behavior of readily solidified Al-Ni-Fe alloys in alpha-Aldecagonal phase region", J. Alloy Compd. 399 ,132, 2005.

[10] Ali. H. Hallem, Talib A. Jasim and Nabaa S. Radhi, "Effect of alumina reinforcement on some mechanical properties of aluminum matrix composites produced by stir casting process, International Journal of Civil Engineering and Technology (IJCIET), Vol.9, Issue 10, pp. 12711280, 2018.

[11] Ali H. Hallem and Nawal Mohammed Dawood, " Investigation the effects of zirconium addition on wear and corrosion behavior of alpha brass alloy $(\mathrm{Cu}-\mathrm{Zn} \mathrm{30)}$, Iternational journal of mechanical engineering, Vol. 9,Issue 12, pp.844-857, 2018.

[12] Dipti Kanta Das, Purena Chandra Mishra, Saranjit Singh and Ratish Kumar Thakur, Properties of ceramic - reinforced aluminum matrix composites - a review, International Journal of Mechanical and Materials Engineering, springer open journal, 2014.

Table (1) Purity and particles size and source of powders used

\begin{tabular}{|l|c|c|l|}
\hline \multicolumn{1}{|c|}{ Powders } & $\begin{array}{c}\text { Average } \\
\text { particle size } \\
(\mu \mathrm{m})\end{array}$ & Purity \% & \multicolumn{1}{c|}{ Origin } \\
\hline Aluminum $(\mathrm{Al})$ & 19.90 & 99.99 & Central Drug House $(\mathrm{p}) \mathrm{Ltd} /$ India \\
\hline Nickel (Ni) & 7.723 & 99.88 & Central Drug House $(\mathrm{p}) \mathrm{Ltd} /$ India \\
\hline Silicon Carbide(SiC) & 10.04 & 99.95 & Central Drug House $(\mathrm{p}) \mathrm{Ltd} /$ India \\
\hline
\end{tabular}

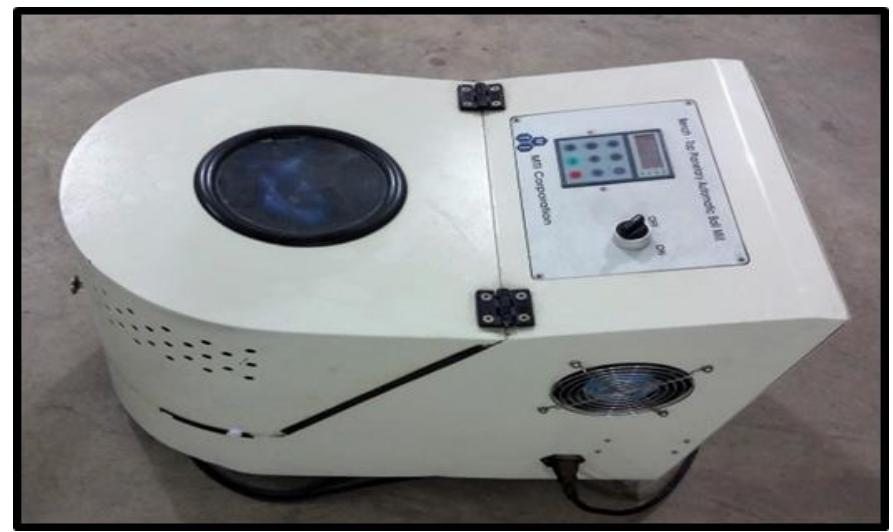

Fig. (1): Bench-Top Planetary Automatic Ball Mil. 


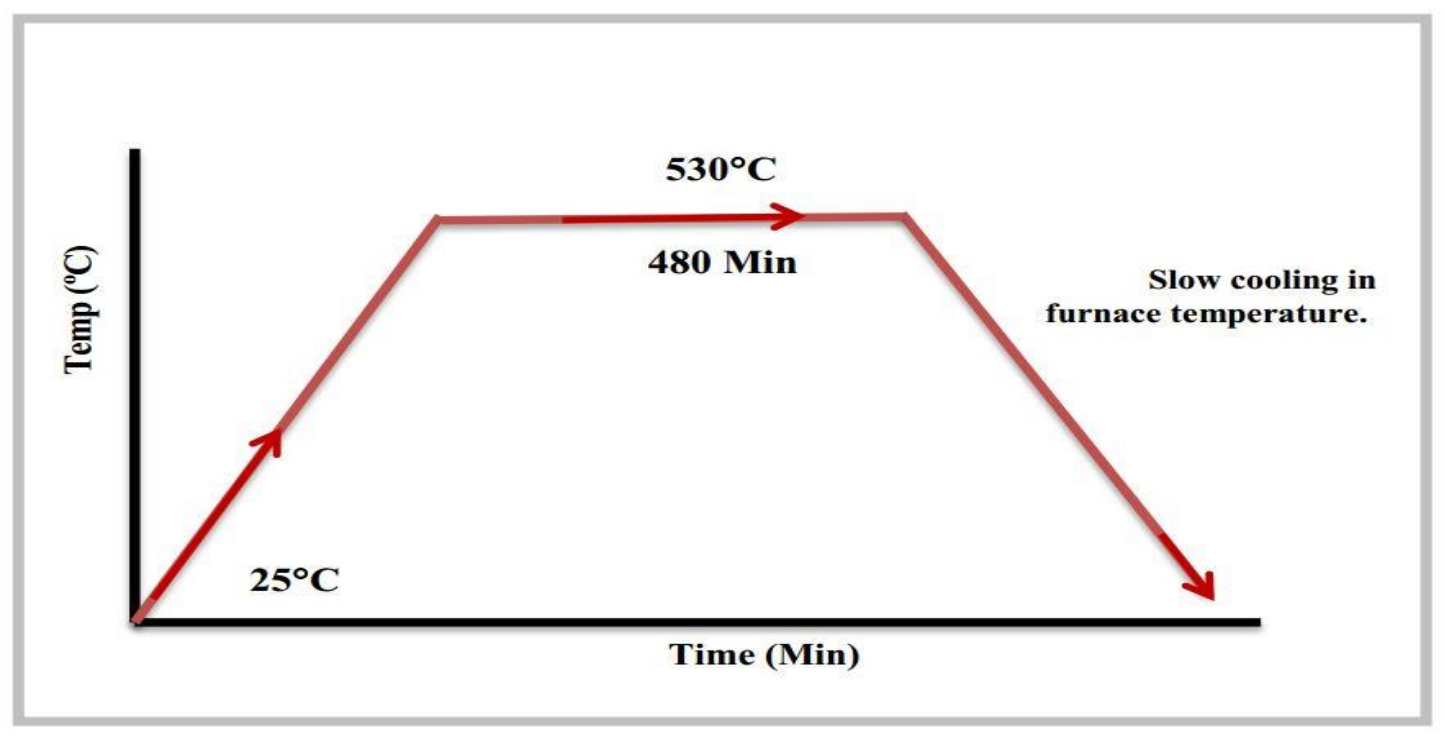

Fig. (2): Thermal Cycle Used in third attempt of sintering.
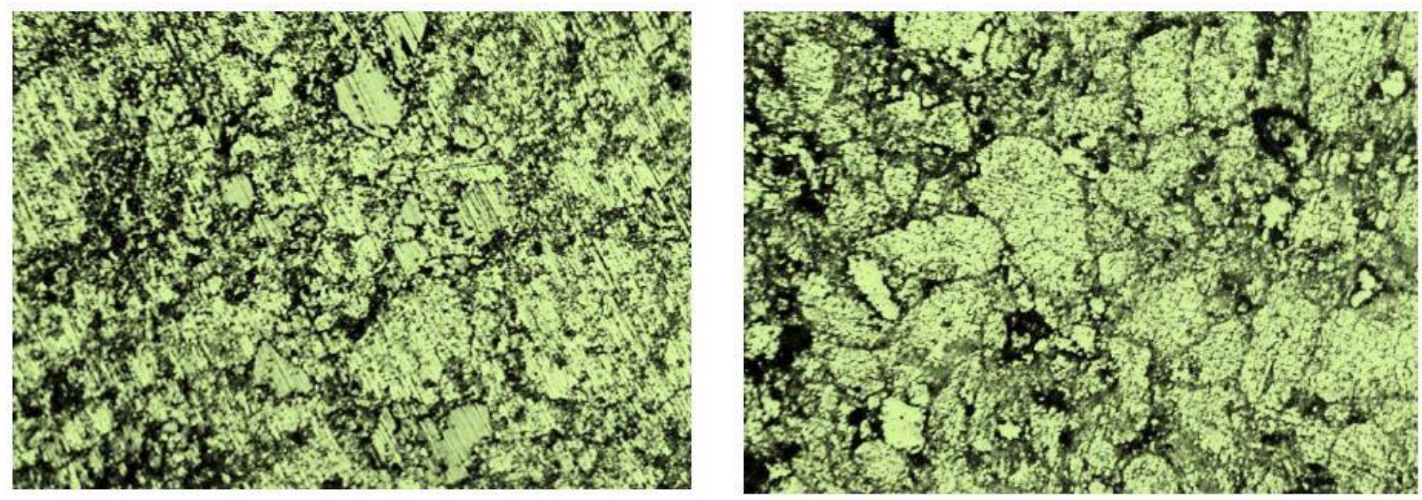

Fig. (3) Microstructure for $\mathrm{Al20} \% \mathrm{Ni}$ and $\mathrm{Al20} \% \mathrm{Ni}+8 \% \mathrm{SiC}$ alloys after sintering and etching (200x).

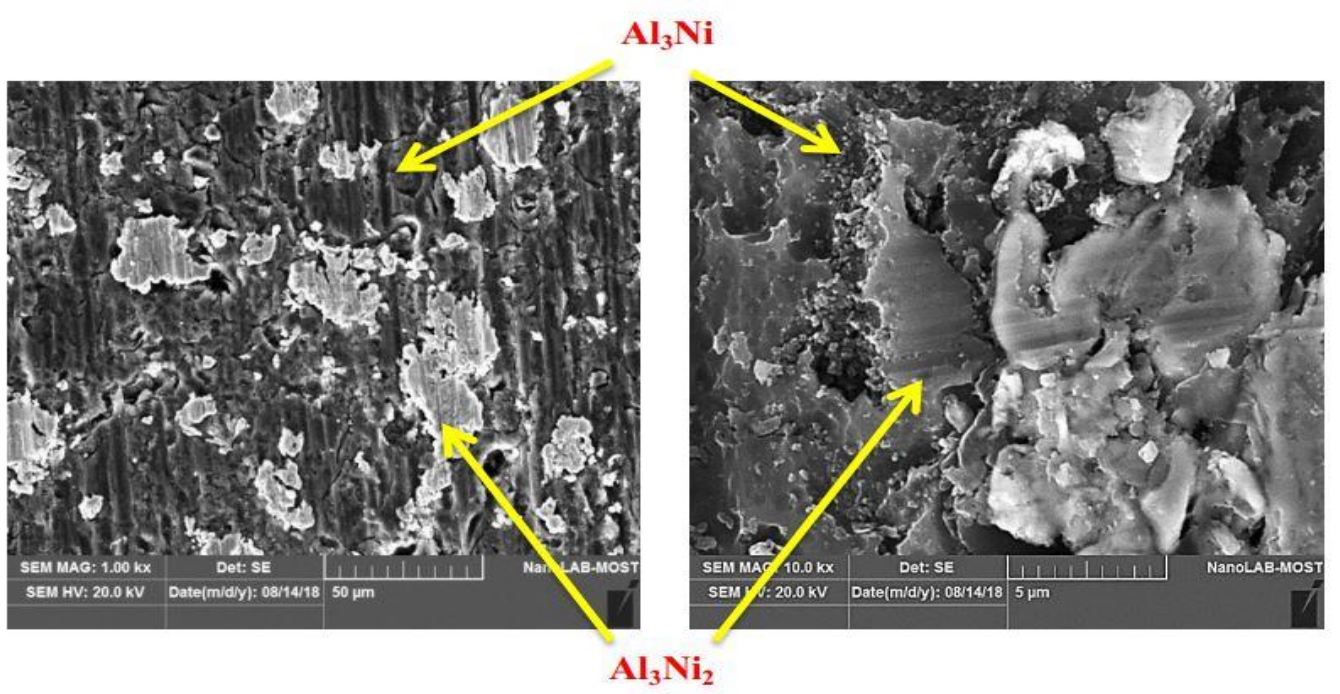

Fig. (4) SEM images for etched A120\%Ni alloy with different magnification. 

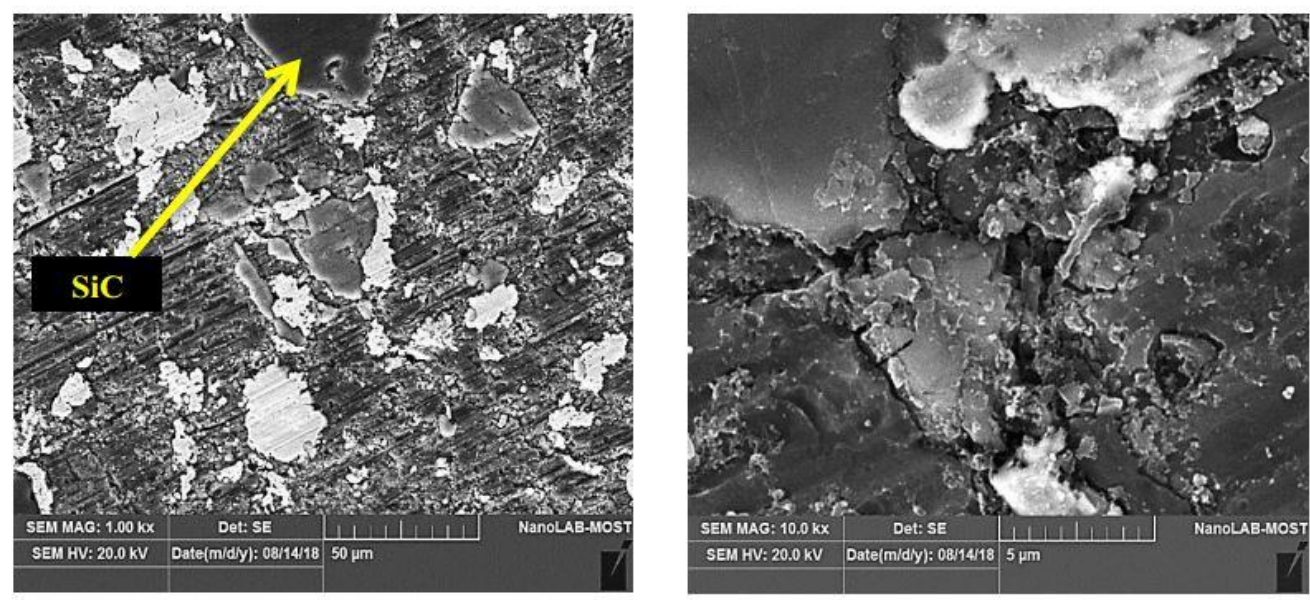

Fig.(5) SEM images for etched $\mathrm{Al20} \% \mathrm{Ni}+8 \% \mathrm{SiC}$ alloy with different magnification.

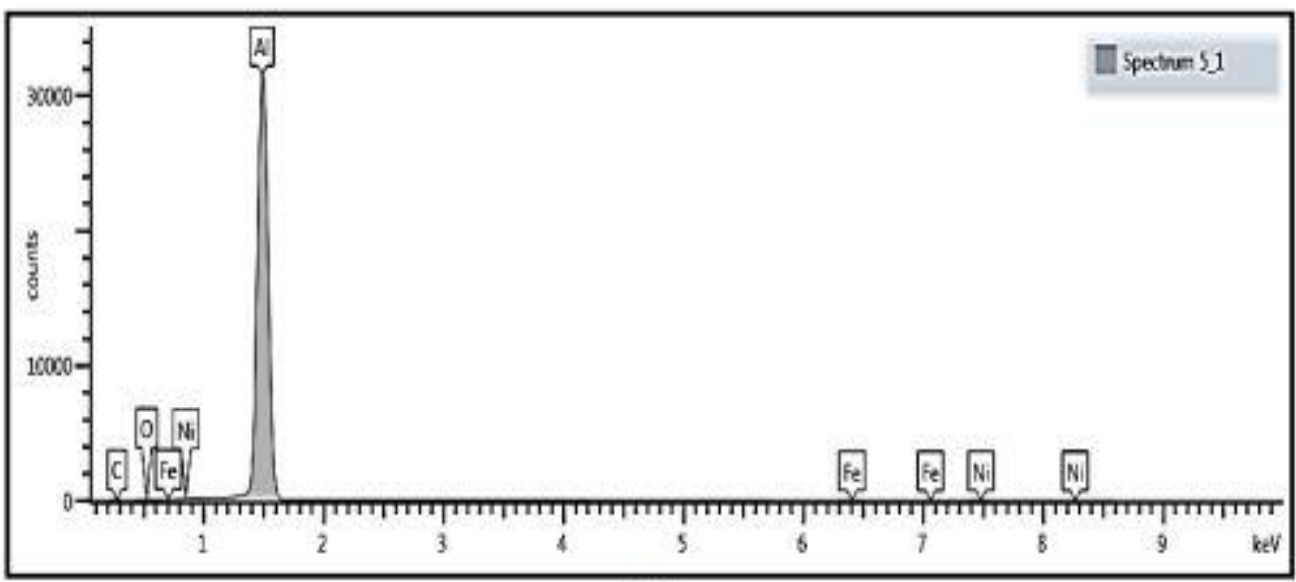

(A)

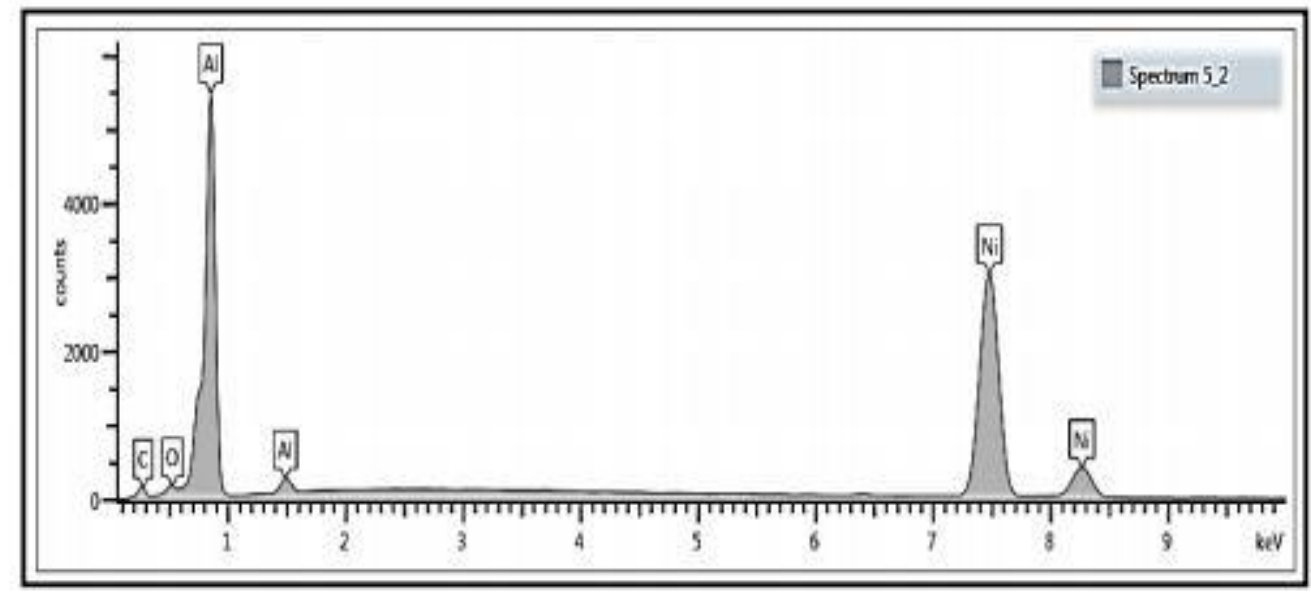

(B) 


\section{Electron Image $\mathbf{5}$}

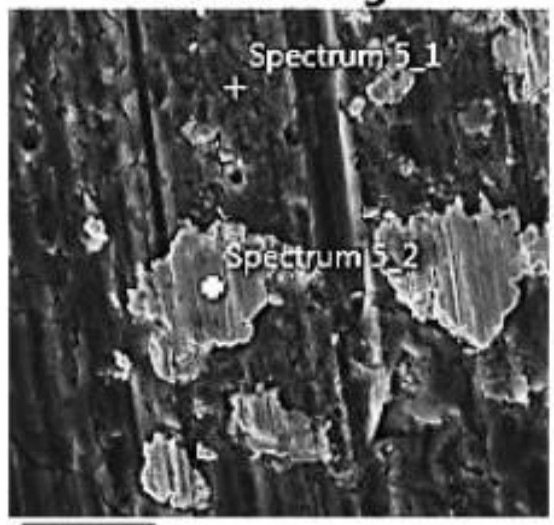

$\longdiv { 2 5 \mu m }$
Electron Image 5

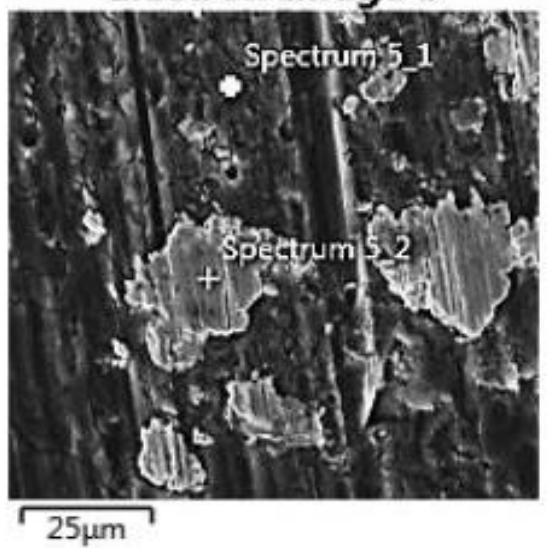

(C)

Fig.(6) : (A) and (B) EDS Spectrum analyses, (C) mapping for $\mathrm{Al}$ and $\mathrm{Ni}$ for Alloy $\mathrm{Al} 20 \% \mathrm{Ni}$.

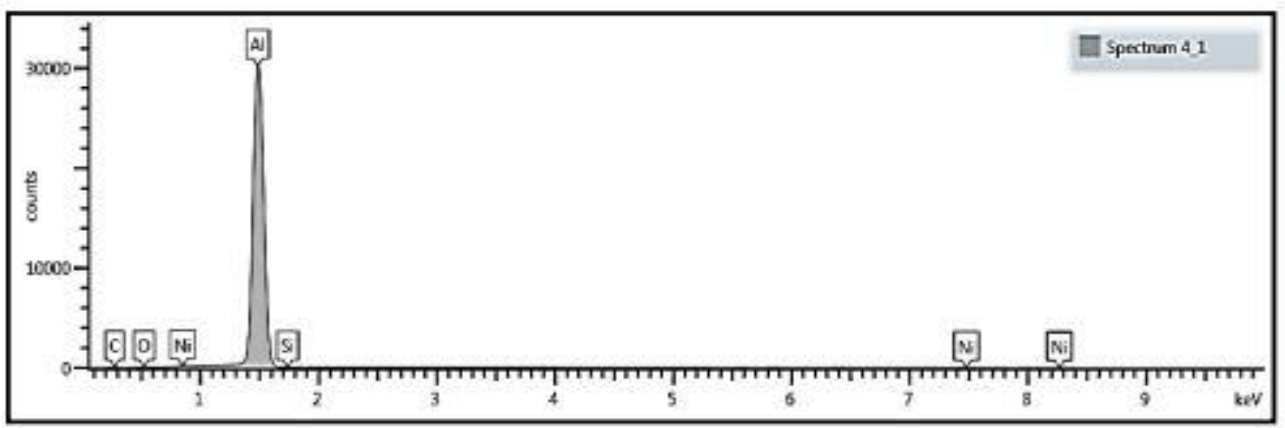

(A)

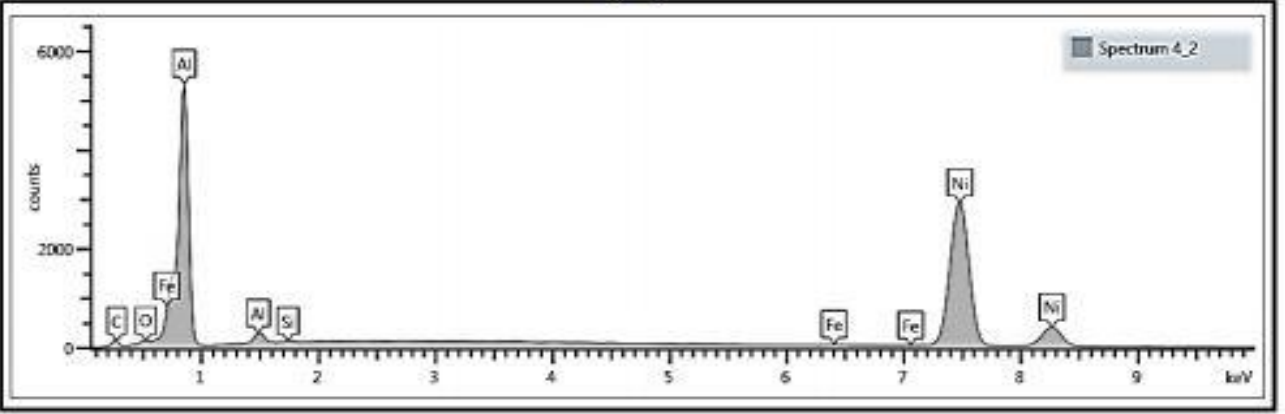

(B)

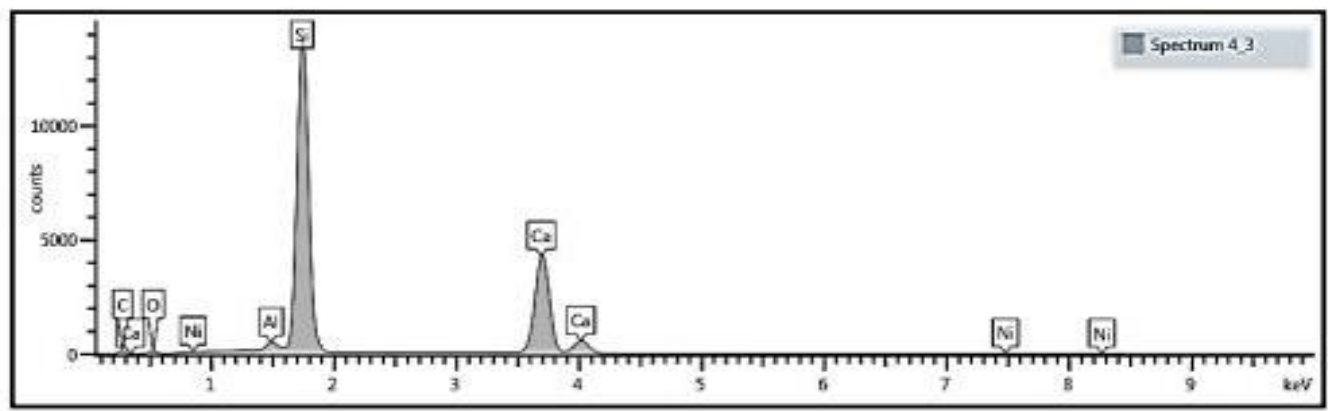

(c) 


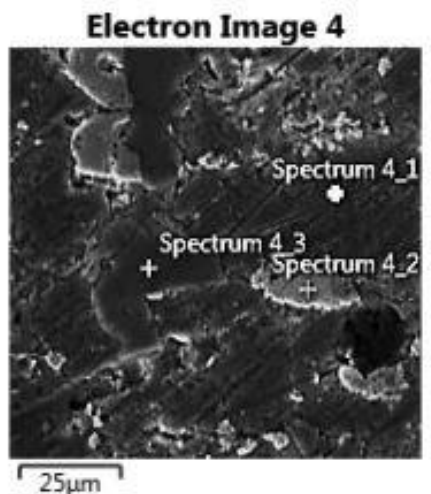

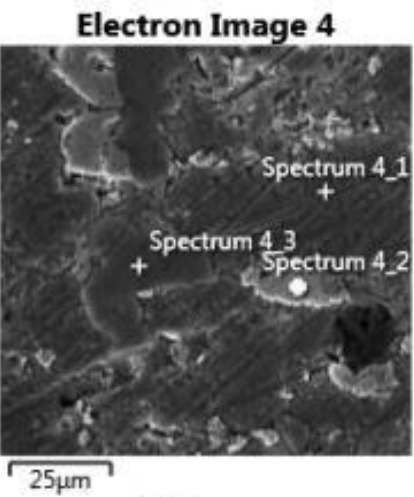

(D)

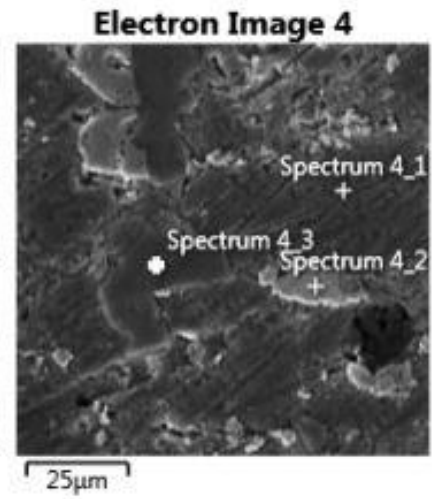

$\longdiv { 2 5 \mu \mathrm { m } }$

Fig.(7):(A-B and C) EDS Spectrum analyses, ( D) mapping for $\mathrm{Al}$ and $\mathrm{Ni}$ for $\mathrm{Alloy} \mathrm{Al} \mathbf{2 0} \% \mathrm{Ni}+8 \% \mathrm{SiC}$.

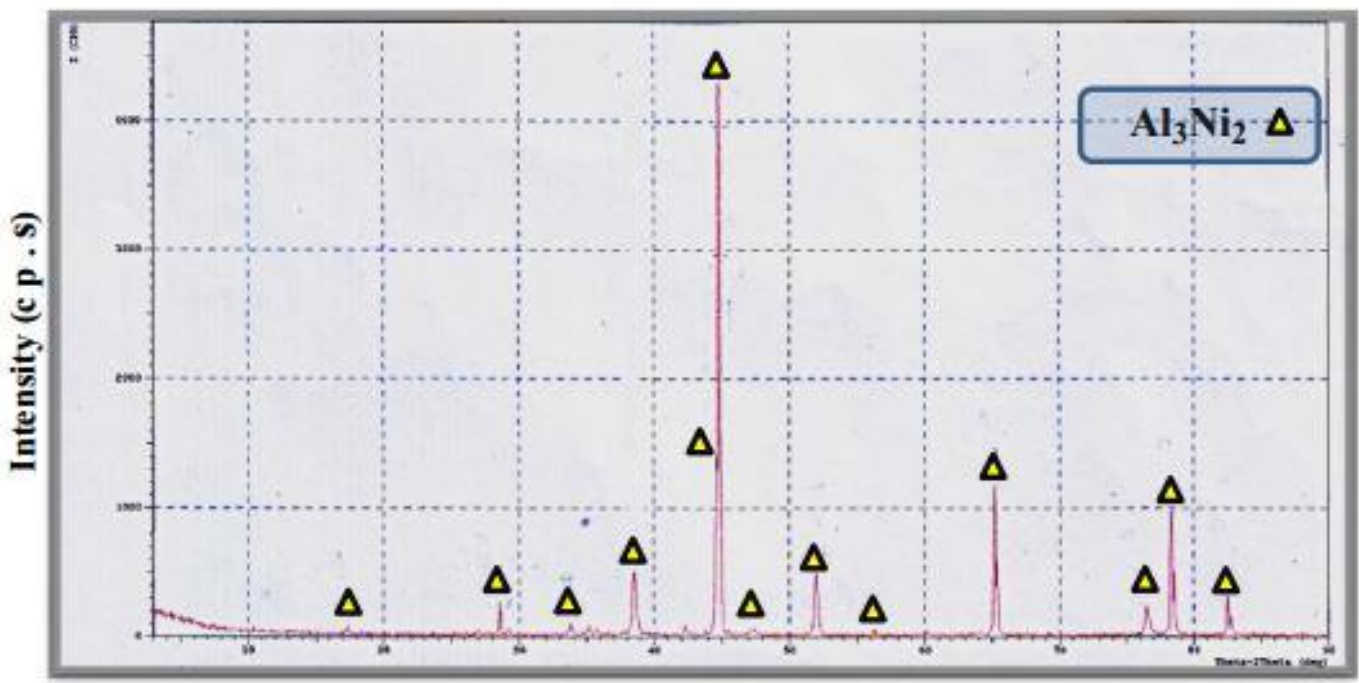

Diffraction angle, $2 \boldsymbol{\theta}$ (dgree)

Fig. (8) XRD pattern for $\mathrm{Al} 20 \% \mathrm{Ni}+8 \% \mathrm{SiC}$ after sintering.

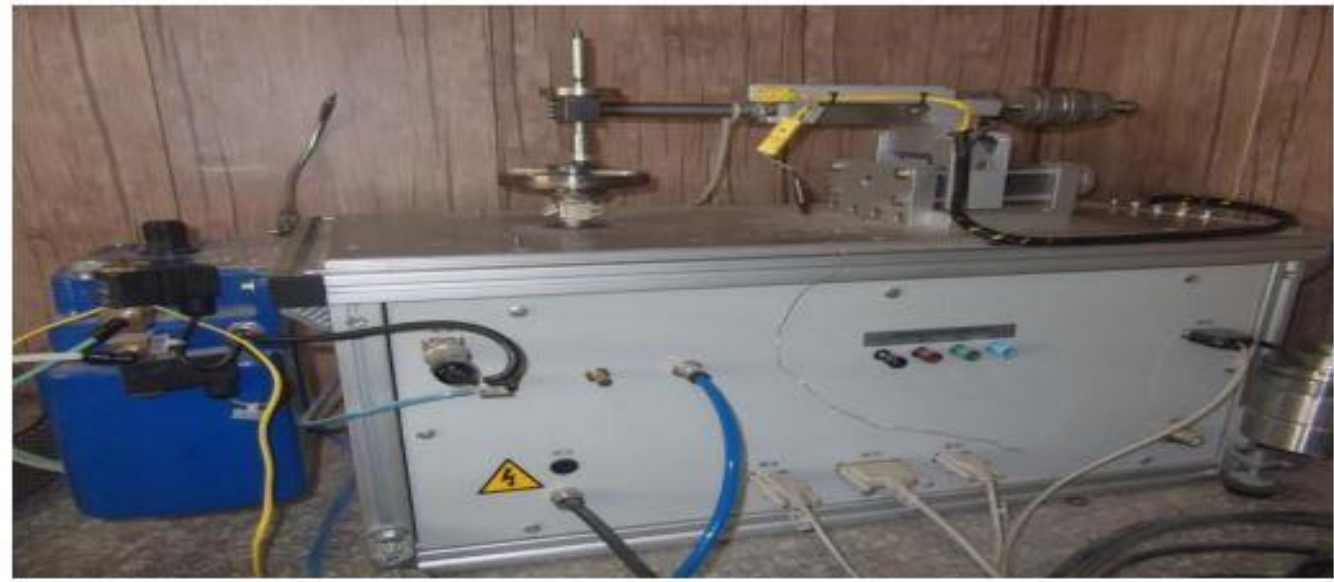

Fig.(9): pin -on - disk wear instrument type (MT-4003 version 10.0). 


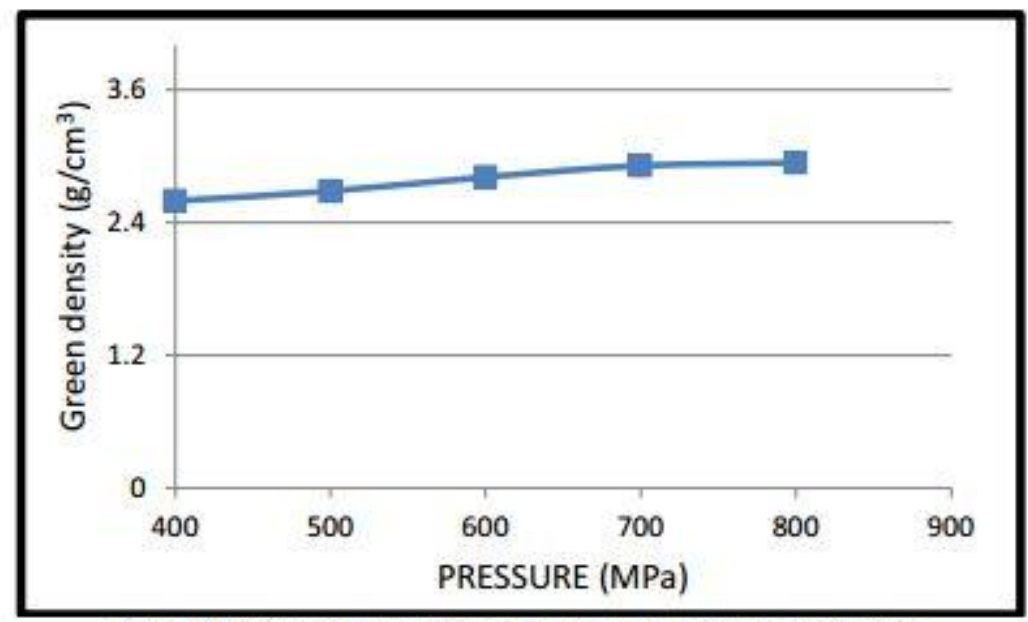

Fig.(10) Green density vs. pressure before sintering

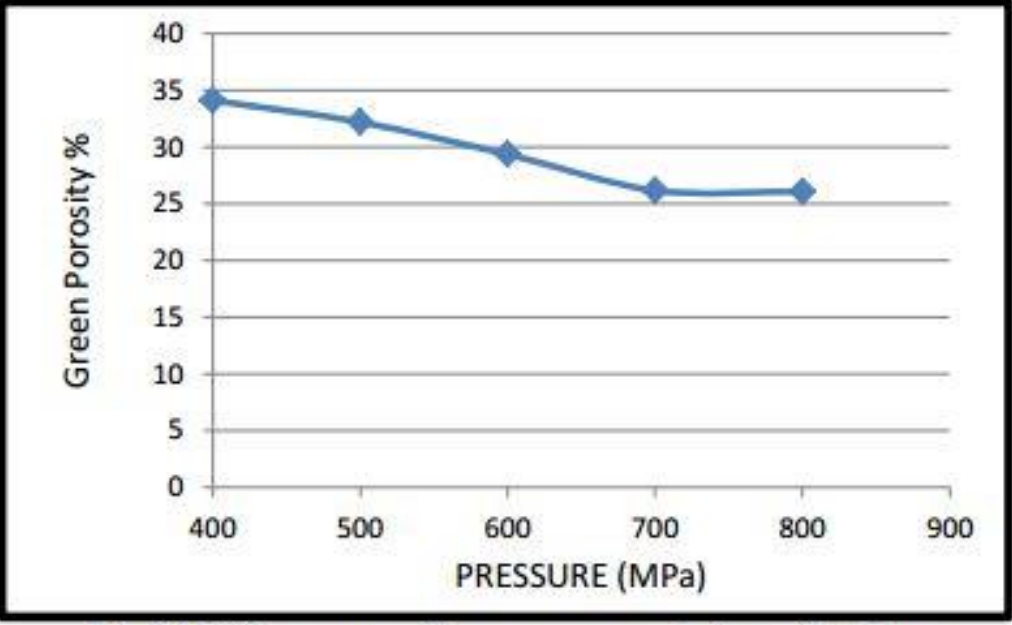

Fig. (11) Green porosity vs. pressure before sintering

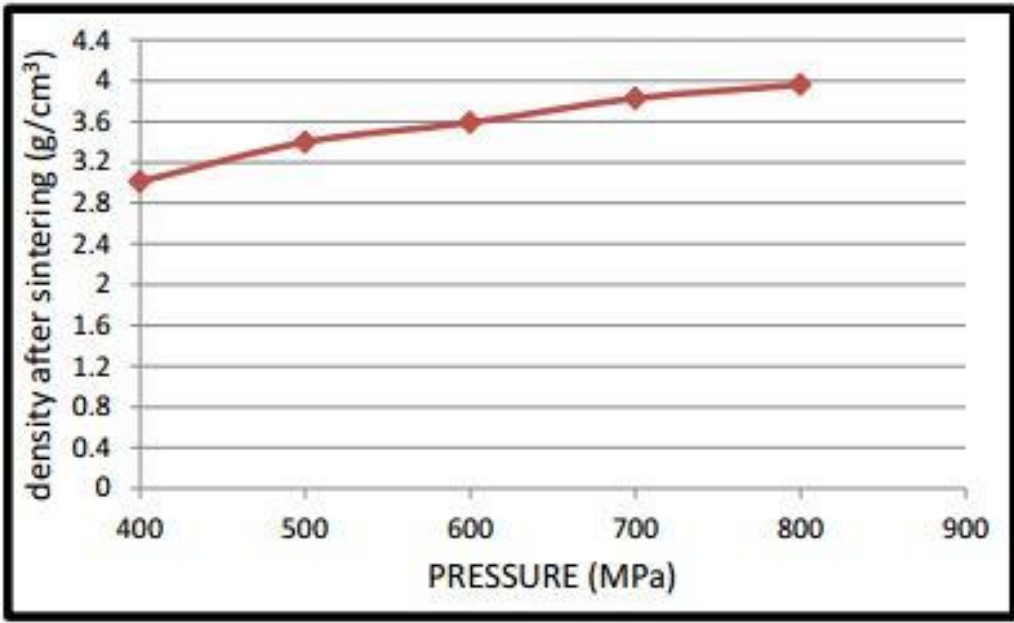

Fig. (12) density after sintering vs. pressure 


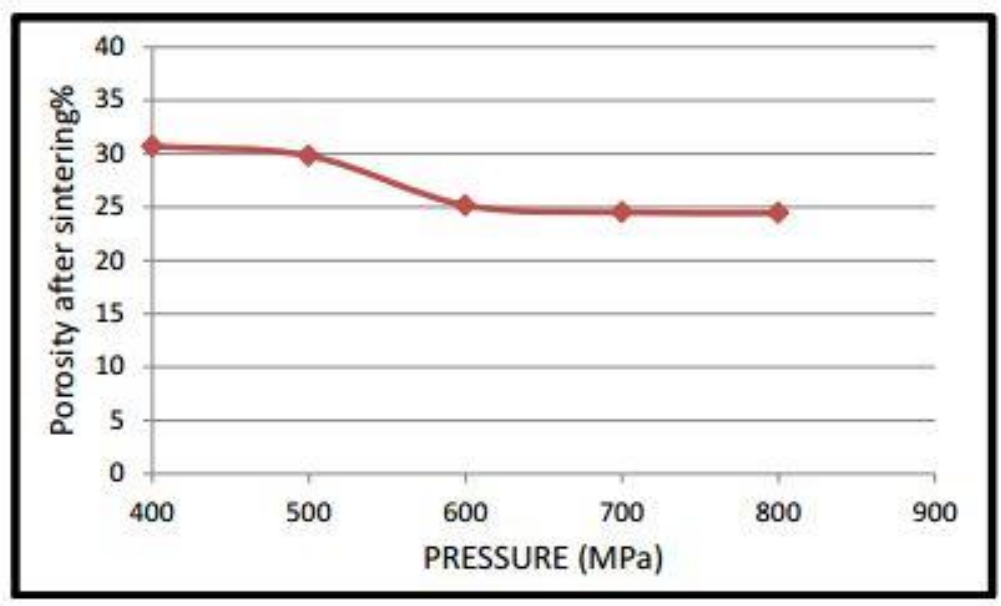

Fig. (13) porosity after sintering vs. pressure after sintering (at $530 \mathrm{C}^{\circ}$ for $8 \mathrm{hr}$ ).

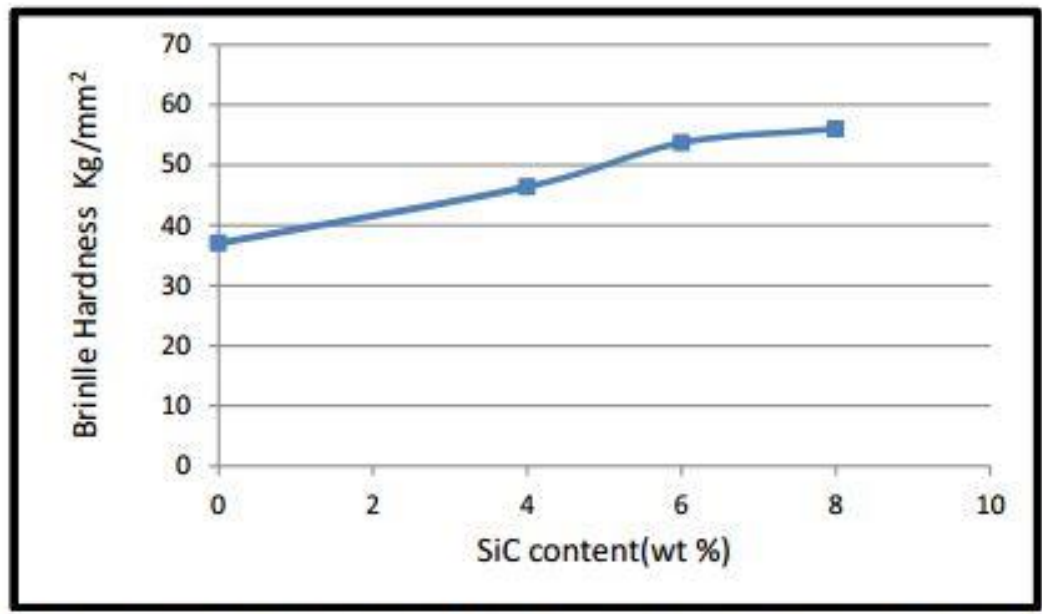

Fig (14) Effect of SiC content on the hardness for alloys with out and with 4-6-8 wt.\% SiC.

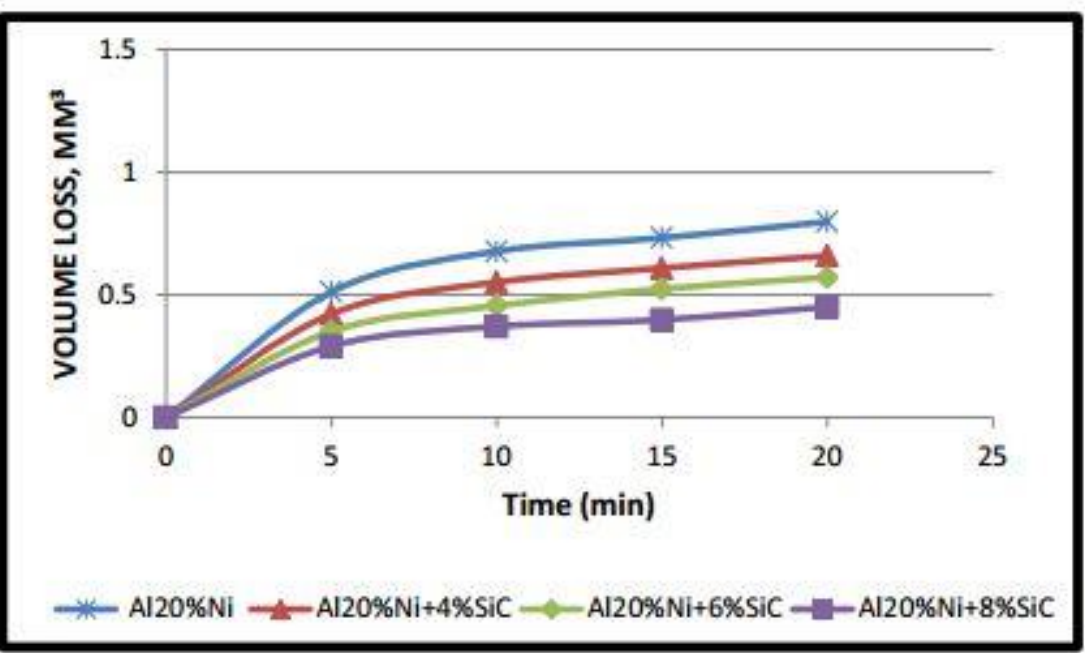

Fig. (15): Effect of SiC particles on wear rate at (10N) load. 


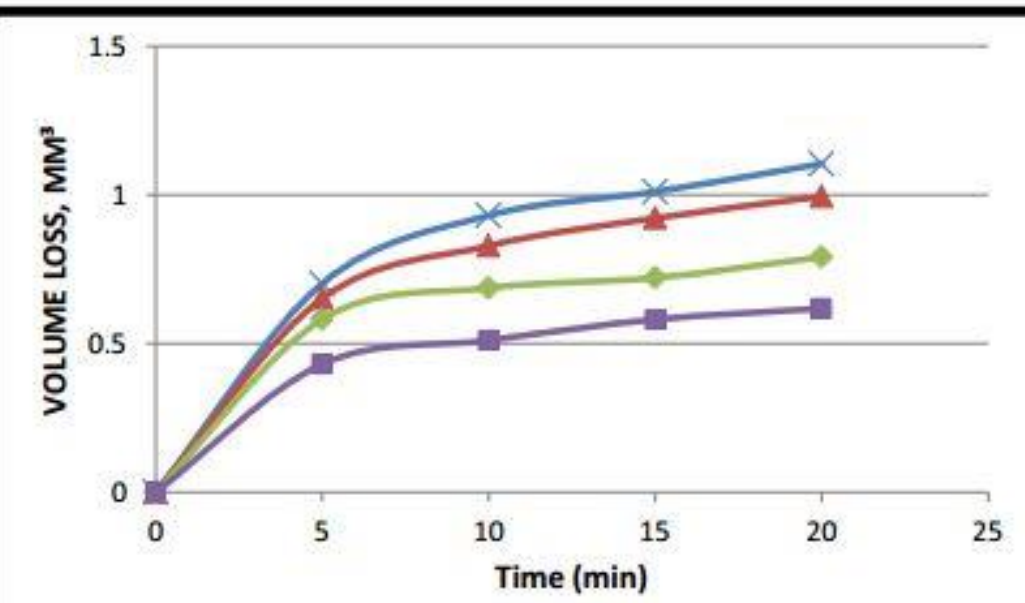

$\longrightarrow \mathrm{Al} 20 \% \mathrm{Ni} \longrightarrow \mathrm{Al} 20 \% \mathrm{Ni}+4 \% \mathrm{SiC} \longrightarrow \mathrm{Al} 20 \% \mathrm{Ni}+6 \% \mathrm{SiC}=\mathrm{Al} 20 \% \mathrm{Ni}+8 \% \mathrm{SiC}$

Fig. (16): Effect of $\mathrm{SiC}$ particles on wear rate at (20N) load.

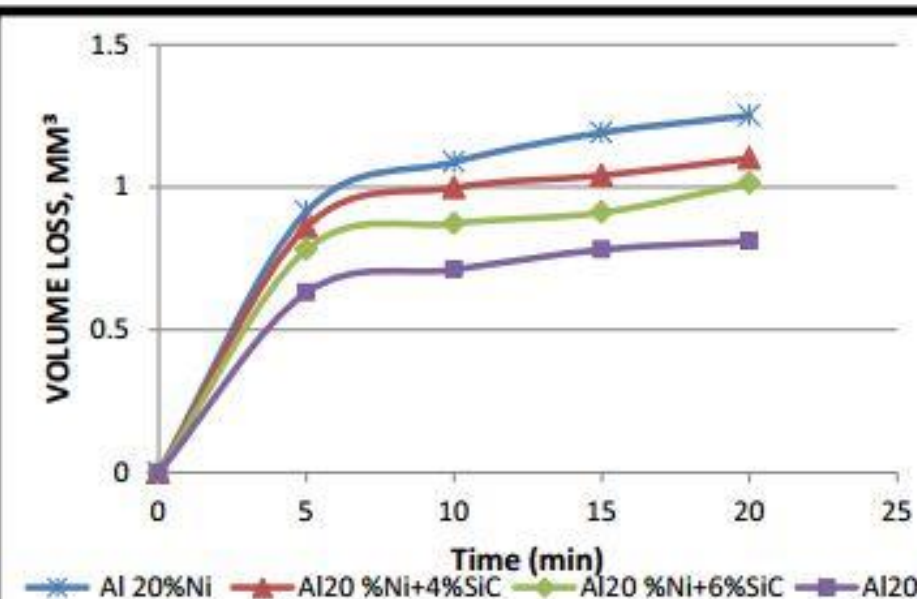

- Al $20 \% \mathrm{Ni} \longrightarrow \mathrm{Al} 20 \% \mathrm{Ni}+4 \% \mathrm{SiC}-\mathrm{Al} 20 \% \mathrm{Ni}+6 \% \mathrm{SiC}=\mathrm{Al} 20 \% \mathrm{Ni}+8 \% \mathrm{SiC}$

Fig. (17): Effect of $\mathrm{SiC}$ particles on wear rate at (30N) load.

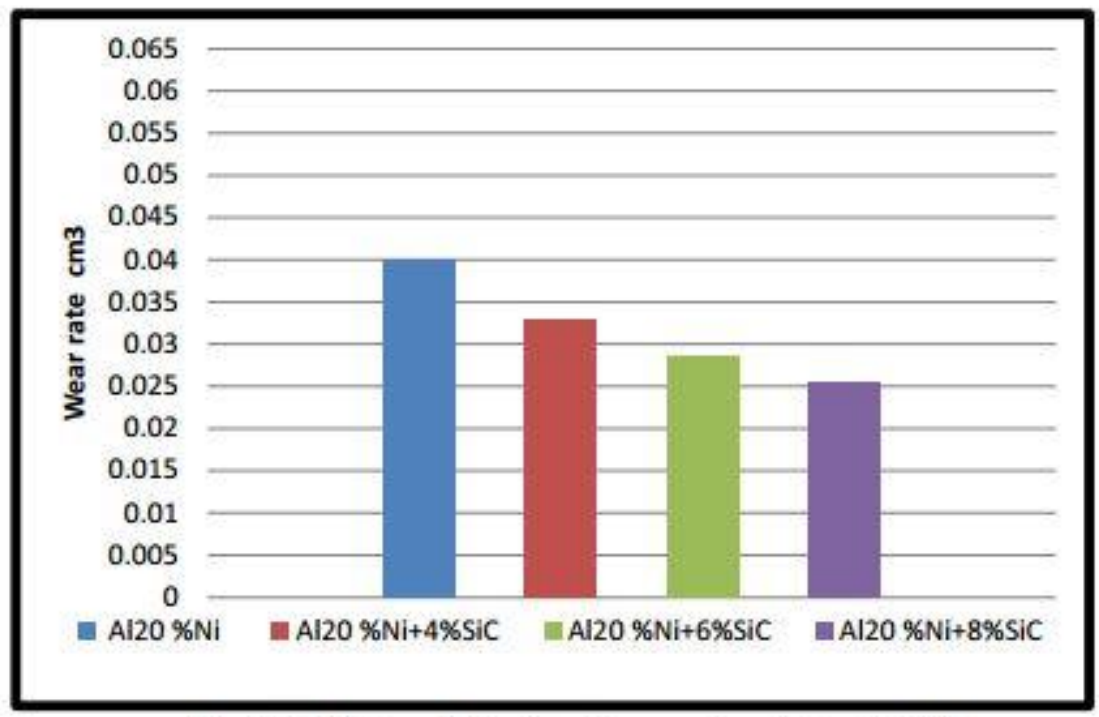

Fig. (18): Wear Rate for all samples at Load $10 \mathrm{~N}$. 


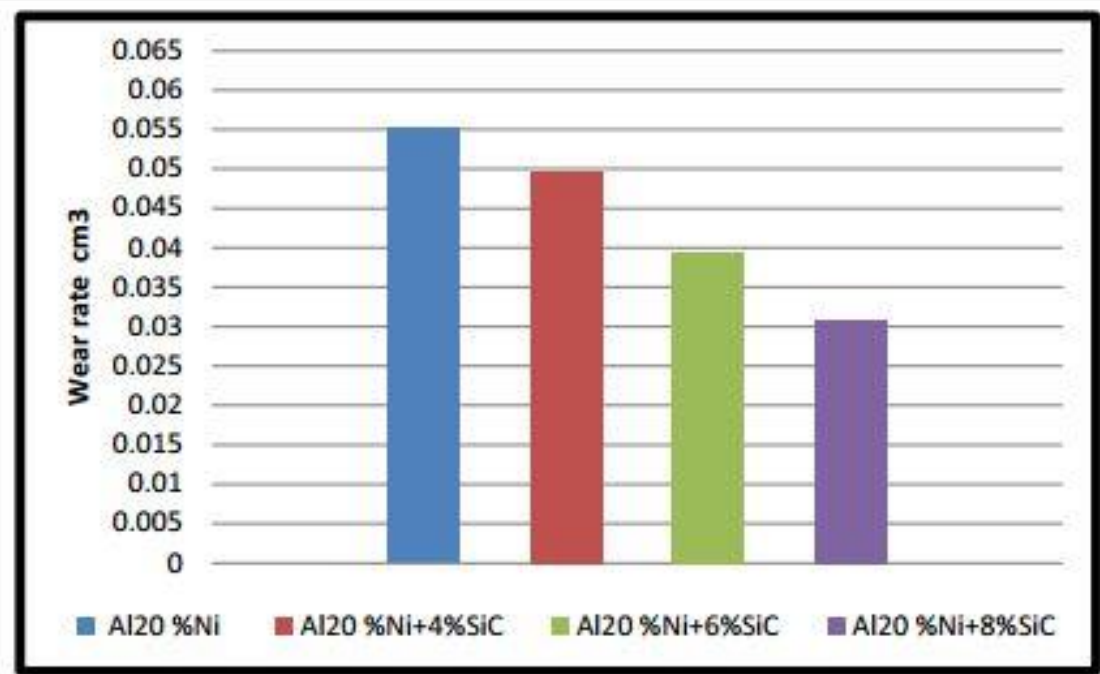

Fig. (19): Wear Rate for all samples at Load $20 \mathrm{~N}$.

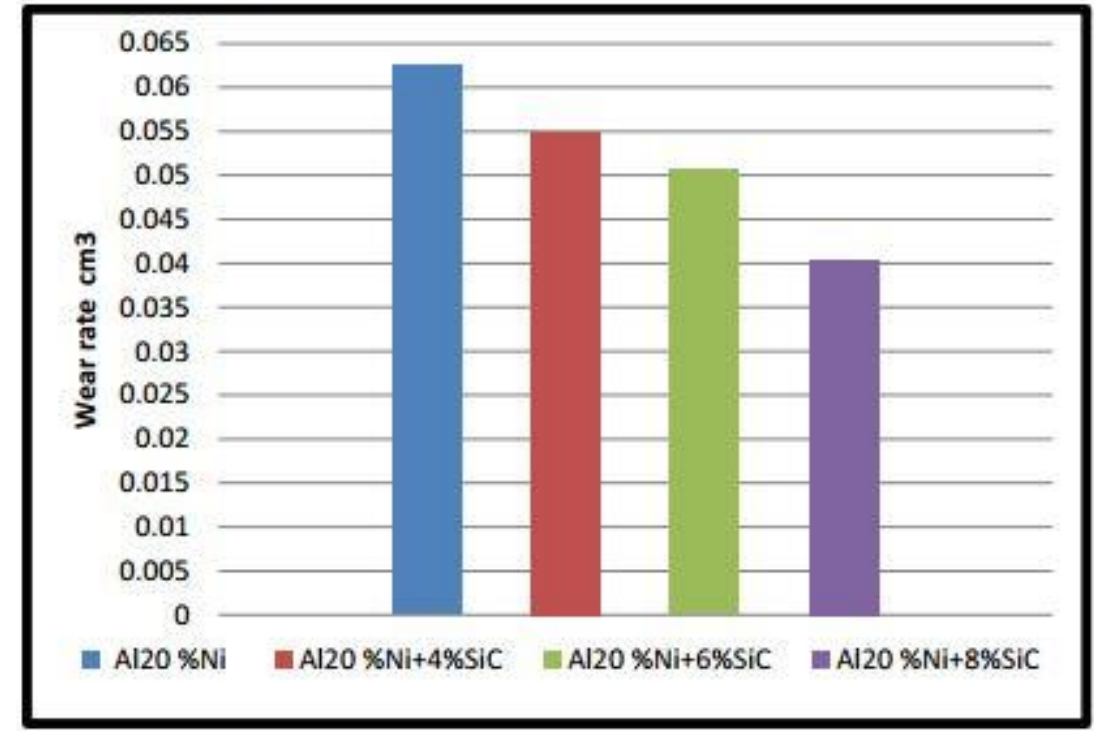

Fig. (20): Wear Rate for all samples at Load $30 \mathrm{~N}$. 


\section{تأثير إضافة كربيد السيليكون على الخصائص الميكانيكية لمكبوسات الامنيوم نيكل المنتجة بواسطة ميتالورجيا المساحيق

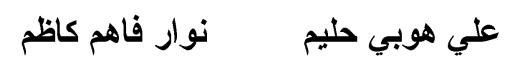 كلية هندة الدواد، جامعة بابل، بابل، العراق} alialihhhobi@gmail.com

يهدف هذا العمل إلى إنتاج سبائك Al-Ni بو اسطة تقنية ميتالورجيا المساحيق بسبب أهميتها التجارية و التكنولوجية. تم قياس حجم دقائق مساحيق النيكل والألمنيوم ثم خلطت المساحيق مع النسبة المئوية (20\%) (NiC) و أضيف مسحوف كربيد السيليكون (SiC) إلى مسحوق السبائك الرئيسي بنسبة (8\%-6-4 وزنية) على التو الي، ثم خلطت هذه المساحيق للحصول على توزيع متجانس، ثم ثم

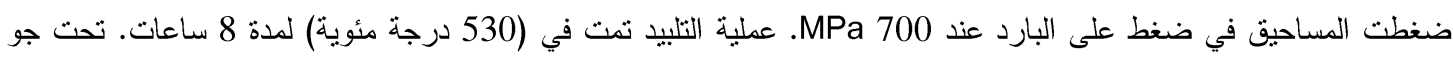
مفرغ (10)

وبعد التبريد نم صقل هذه العينات لتقييم البنية المجهرية و الكثافة و المسامية واجريت اختبار ات LOM ،EDS، SEM، حيود

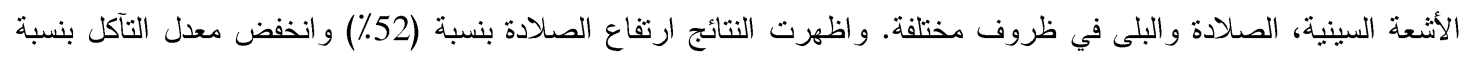
(55\%) عند إضافة 8\% بالوزن كربيد السيليكون، حيث كانت أفضل النتائج. الكلمات اللاله: ـ المو اد المركبة، سبائك الالمنيو م- نيكل، تكنولوجيا المساحيق، AMMCs. 